\title{
ON A METHOD FOR DETERMINING THE NEUTRAL SURFACE OF THE LAMINATED MONOLITH COMPOSITES
}

\author{
RADU I. IATAN ${ }^{1 *}$, GEORGIANA LUMINIȚA ENĂCHESCU ${ }^{1}$, PAVEL GH. \\ FLORESCU $^{1}$
}

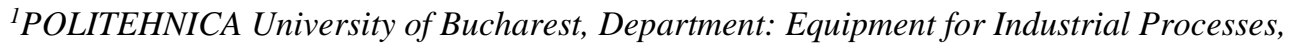
Splaiul Independentei no. 313, sector 6, Bucharest, Romania
\end{abstract}

\begin{abstract}
This paper approaches the methodology for determining the neutral surface of a layered composite. It is to be neglected the spins effect on normal sectional unit load, respectively the influence of the specific linear movements when calculating the bending and torsion of the unit moments. It enables the distribution of tasks specified in the layers' level for evaluating maximum stresses and comparing them to the existing structure of the materials existing in the structure.
\end{abstract}

Keywords: layered composite, neutral surface, specific strains

\section{INTRODUCTION}

The safety of the operation of the industrial mechanical equipment in general, and of those performing the processing of various chemicals, under difficult conditions in terms of the action of operating parameters (pressure, temperatures and chemical and/ or mechanical aggressiveness), in particular, involves a careful attention in choosing the materials compatible to practical cases in the design, manufacture and maintenance, as technical and legal decision-makers.

From the category of the mechanical structures under pressure take part implicitly flat or curved sheets, made of metallic one - piece materials or laminated composites whose layers are joined with adequate adhesive suitable for concrete mechanical and thermal strains [1 - 12].

In the correct assessment of the states of stress and strain in the structure of plates and the identification of the most requested referral areas whose intensities should be below the normalized/ standardized values requires finding their neutral position of the surface. The difficulty is distinguished more difficult for laminated composite sheets rather than the sheets made from the same material [13 - 15].

This paper aims to establish the position of the neutral surface section of an anisotropic or orthotropic plate, structural or constructive (reinforcing nervures, for example). In this way we can achieve a true assessment of the strain states (stresses and strains), both for static actions, and the dynamic ones [17]. In this way:

- The specific linear deformations and the rotations of a volume element of an anisotropic plate with elastic, mechanical and thermal properties dependent, meanwhile, on the position in the cross section, are to be considered;

- Sectional efforts are written expressions (normal and shear unitary forces), as well as bending and torsional unitary moments;

\footnotetext{
* Corresponding author, email: $\underline{\text { r_iatan@yahoo.com }}$

(C) 2016 Alma Mater Publishing House
} 
- It is to be neglected the effect of the flexures in the structure of the expressions of the normal unitary strengths, respectively of the specific linear strains during the unitary bending and twisting moments;

- Taking into account the previous acceptation by cancelling the appropriate expressions and introducing a convenient change of a thickness variable on the considered plate regarded it is to be deducted the relation for the calculation of the position of the neutral surface, along an axis of the reference system;

- Exemplifying is produced on a structure with one or more layers, specific to layered composites;

- Based on the study made, simplifying assumptions of calculation are taken into account, in the elastic fields of strains, for thin plates.

The designer analysing a particular type structure of laminated composite boards must adopt a certain value in the calculation necessary to estimate the states of stress and a convenient arrangement of layers, linking them to the operating parameters. Relations are established for calculating the loads distributed across layers (uniform tension/ compression forces, shear forces, respectively forces of the uniform bending and torsion moments) and of the maximum tensions which compares with the allowable stresses / resistances of the present materials. Ensuring bearing capacity of the structure imposes a certain convenient order of the composite layers.

\section{SIMPLIFYING CALCULATION ASSUMPTIONS}

The economy of materials, and the safe operation of the mechanical construction and, require a careful analysis of stresses states and strains developed under the action of external loads. Therefore, the result of the calculations depends essentially on the adopted simplifying assumptions [18 - 20]:

- Laminated thin plates are considered to be of uniform/constant thickness.

- Laminated plates consist of orthotropic parallel laminae with intimate contact (glued among them, resulting in their deformation equality - displacements and rotations - at interfaces level.

- No slip occurs between layers.

- The deformations produced are small ( the arrow of the plate should be below $20 \%$ of its thickness [18 - 21]; the length of the neutral fiber remains virtually unchanged at bending strain, being neglected in relation to the unit.

- Each layer has a linear elastic behaviour, respecting the law of R. Hooke.

- Any of the layers is in a state of flat stress (the normal stresses on planes parallel to the neutral surface of the plate is to be neglected relative to the others).

- Keep the A. E. H. Love - R. G. Kirchhoff hypothesis (undistorted surface normal remain normal to these after their deformation - assuming the hypothesis of the straights normal).

- Strains and stresses overlap algebraic to evaluate overall stresses.

- It is assumed that initial stresses (internal /interior) are missing.

- Do not take into account the speed of straining of the plates.

\section{THERMAL AND MECHANICAL STRESSES AND STRAINS IN A LIGHT/ (LAYER OF A LAYERED COMPOSITE)}

Note: It is accepted the case when elastic and thermal characteristics of the material - longitudinal and transverse modulus, the coefficient of transverse contraction and the thermal deformation factor -are dependent on temperature.

In terms of the request of the elastic area (by accepting R. Hooke's law), the linear and angular strains for an orthotropic structure, is presented in the form [16]:

$$
\begin{aligned}
& e_{x}=\frac{1}{E_{x}(T, z)} \cdot \sigma_{x}-\frac{v_{y}}{E_{y}(T, \mathrm{z})} \cdot \sigma_{y}+\alpha_{T x}(T, z) \cdot T(x, y, z) ; \\
& e_{y}=\frac{1}{E_{y}(T, z)} \cdot \sigma_{y}-\frac{v_{x}}{E_{x}(T, z)} \cdot \sigma_{x}+\alpha_{T y}(T, z) \cdot T(x, y, z) ;
\end{aligned}
$$




$$
e_{x y}=\tau_{x y} /\left[G_{x y}(T, z)\right]
$$

holds for correspondence [18, 22 - 25]:

$$
E_{x} \cdot v_{y}=E_{y} \cdot v_{x}
$$

The equalities (1) - (3) can be put into form:

$$
\begin{gathered}
\sigma_{x}=\frac{E_{x}(T, z)}{1-v_{x} \cdot v_{y}} \cdot\left\{e_{x}+v_{y} \cdot e_{y}-\left[\alpha_{T x}(T, z)+v_{y} \cdot \alpha_{T y}(T, z)\right] \cdot T(x, y, z)\right\} ; \\
\sigma_{y}=\frac{E_{y}(T, z)}{1-v_{x} \cdot v_{y}} \cdot\left\{e_{y}+v_{x} \cdot \varepsilon_{x}-\left[\alpha_{T y}(T, z)+v_{x} \cdot \alpha_{T x}(T, z)\right] \cdot T(x, y, z)\right\} ; \\
\tau_{x y}=G_{x y}(T, z) \cdot e_{x y} .
\end{gathered}
$$

According to the hypothesis of straight normal, there can be written the rules for any fiber located at some distance from the neutral surface of the plate $[16,18]$ :

$$
\begin{gathered}
e_{x}=\varepsilon_{x}+z \cdot \chi_{x} ; e_{y}=\varepsilon_{y}+z \cdot \chi_{y} ; e_{x y}=\gamma_{x y}+2 \cdot z \cdot \chi_{x y} ; \\
\varepsilon_{x}=\partial u / \partial x ; \quad \varepsilon_{y}=\partial v / \partial y ; \quad \gamma_{x y}=\partial u / \partial y+\partial v / \partial x ; \\
\chi_{x}=-\partial^{2} w / \partial x^{2} ; \quad \chi_{y}=-\partial^{2} w / \partial y^{2} ; \quad \chi_{x y}=-\partial^{2} w /(\partial x \cdot \partial y),
\end{gathered}
$$

$u, v, w$ stand for the displacement points of the board along the axes of the reference system $\mathrm{O} x \mathrm{yz}$, attached to the plate.

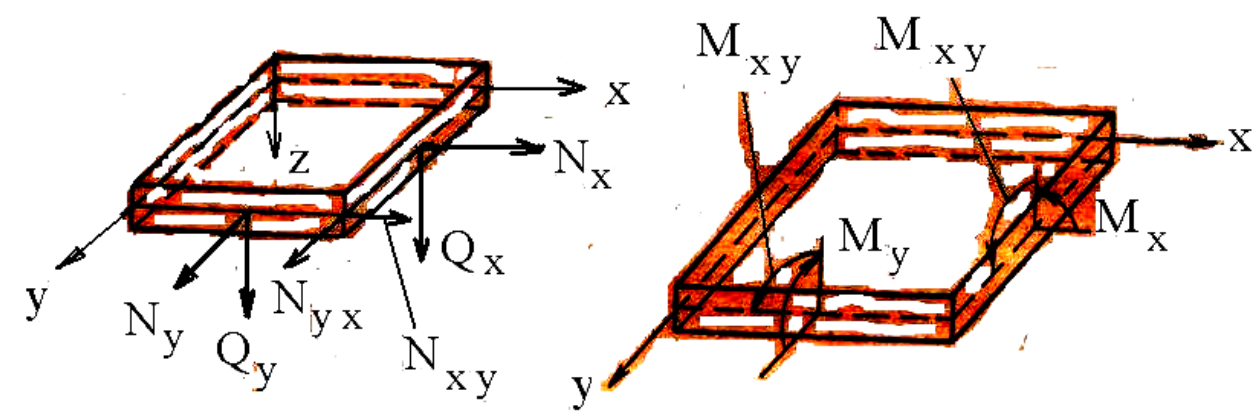

Fig. 1. Uploading a volume element of a rectangular flat plate [16].

Note: Curves $\chi_{x}, \chi_{y}$ and $\chi_{x y}$ may be disregarded in value compared to other quantities so that: $e_{x} \approx \varepsilon_{x}$; $e_{y} \approx \varepsilon_{y} ; e_{x y} \approx \gamma_{x y}$. Also, in writing Equality (9) was held that [16]:

$$
\begin{gathered}
(\partial w / \partial x)^{2}\left\langle<(\partial u / \partial x),(\partial w / \partial y)^{2}\langle\langle(\partial v / \partial y) \text { and }\right. \\
{[(\partial w / \partial x) \cdot(\partial w / \partial y)]<<[(\partial u / \partial y)+(\partial v / \partial x)]}
\end{gathered}
$$


which is why they remained in the study forms provided.

From Equalities (5) - (7) are set the expressions of the normal elastic efforts $\left(N_{x}, N_{y}\right)$ - normal unit forces and shear $\left(N_{x y}\right)$ - cutting unit forces -, or respectively of the moments unit of bending $\left(M_{x}, M_{y}\right)$ and unit the twisting moments unit $\left(M_{x y}\right)$ - Figure 1 - [16]:

$$
\begin{aligned}
& N_{x}=B_{11}(x, y, z) \cdot \varepsilon_{x}+B_{12}(x, y, z) \cdot \varepsilon_{y}+A_{11}(x, y, z) \cdot \chi_{x}+ \\
& +A_{12}(x, y, z) \cdot \chi_{y}-N_{1 T}(x, y, z) \text {; } \\
& N_{y}=B_{12}(x, y, z) \cdot \varepsilon_{x}+B_{22}(x, y, z) \cdot \varepsilon_{y}+A_{22}(x, y, z) \cdot \chi_{y}+ \\
& +A_{12}(x, y, z) \cdot \chi_{y}-N_{2 T}(x, y, z) \text {; } \\
& N_{x y}=B_{33}(x, y, z) \cdot \gamma_{x y}+2 \cdot A_{33}(x, y, z) \cdot \chi_{x y} ; \\
& M_{x}=D_{11}(x, y, z) \cdot \chi_{x}+D_{12}(x, y, z) \cdot \chi_{y}+A_{11}(x, y, z) \cdot \varepsilon_{x}+ \\
& +A_{12}(x, y, z) \cdot \varepsilon_{y}-M_{1 T}(x, y, z) \text {; } \\
& M_{y}=D_{22}(x, y, z) \cdot \chi_{y}+D_{12}(x, y, z) \cdot \chi_{x}+A_{22}(x, y, z) \cdot \varepsilon_{y}+ \\
& +A_{12}(x, y, z) \cdot \varepsilon_{x}-M_{2 T}(x, y, z) \text {; } \\
& M_{x y}=2 \cdot D_{33}(x, y, z) \cdot \chi_{x y}+A_{33}(x, y, z) \cdot \gamma_{x y} .
\end{aligned}
$$

The elastic thermal characteristics and temperature dependence of its position in the lamina volume/ layer.

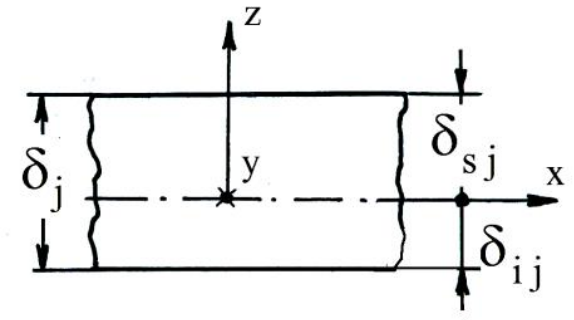

Fig. 2. The neutral position of the surface of the lamina.

Since the modules of longitudinal elasticity $\left(E_{x}, E_{y}\right)$, the coefficient of transverse contraction $\left(v_{x}, v_{y}\right)$ and the factors of thermal deformation $\left(\alpha_{x T}, \alpha_{y T}\right)$ are temperature-dependent, $T=T(x, y, z)$ in turn, based on the coordinates of the points belonging to the volume of the composite, the corresponding sizes of the Equality (11) - (16) have the form [16]:

$$
\begin{gathered}
B_{11}(x, y, z)=\int_{-\delta_{i j}}^{\delta_{s j}} \frac{1}{1-v_{x}(T, z) \cdot v_{y}(T, z)} \cdot E_{x}(T, z) \cdot d z ; \\
B_{12}(x, y, z)=\int_{-\delta_{i j}}^{\delta_{s j}} \frac{v_{y}(T, z)}{1-v_{x}(T, z) \cdot v_{y}(T, z)} \cdot E_{x}(T, z) \cdot d z ;
\end{gathered}
$$




$$
B_{22}(x, y, z)=\int_{-\delta_{i j}}^{\delta_{s j}} \frac{1}{1-v_{x}(T, z) \cdot v_{y}(T, z)} \cdot E_{y}(T, z) \cdot d z
$$

Or

$$
\begin{gathered}
B_{22}(x, y, z)=\int_{-\delta_{i j}}^{\delta_{s j}} \frac{v_{y}(T, z)}{\left[1-v_{x}(T, z) \cdot v_{y}(T, z)\right] \cdot v_{x}(T, z)} \cdot E_{x}(T, z) \cdot d z ; \\
B_{33}(x, y, z)=\int_{-\delta_{i j}}^{\delta_{s j}} G_{x y}(T, z) \cdot d z \\
A_{11}(x, y, z)=\int_{-\delta_{i j}}^{\delta_{s j}} \frac{1}{1-v_{x}(T, z) \cdot v_{y}(T, z)} \cdot E_{x}(T, z) \cdot z \cdot d z \\
A_{12}(x, y, z)=\int_{-\delta_{i j}}^{\delta_{s j}} \frac{v_{y}(T, z)}{1-v_{x}(T, z) \cdot v_{y}(T, z)} \cdot E_{x}(T, z) \cdot z \cdot d z \\
A_{22}(x, y, z)=\int_{-\delta_{i j}}^{\delta_{s j}} \frac{1}{1-v_{x}(T, z) \cdot v_{y}(T, z)} \cdot E_{y}(T, z) \cdot z \cdot d z
\end{gathered}
$$

or

$$
\begin{gathered}
A_{22}(x, y, z)=\int_{-\delta_{i j}}^{\delta_{s j}} \frac{v_{y}(T, z)}{v_{x}(T, z) \cdot\left[1-v_{x}(T, z) \cdot v_{y}(T, z)\right]} \cdot E_{x}(T, z) \cdot z \cdot d z ; \\
A_{33}(x, y, z)=\int_{-\delta_{i j}}^{\delta_{s j}} G_{x y}(T, z) \cdot z \cdot d z ; \\
D_{11}(x, y, z)=\int_{-\delta_{i j}}^{\delta_{s j}} \frac{1}{1-v_{x}(T, z) \cdot v_{y}(T, z)} \cdot E_{x}(T, z) \cdot z^{2} \cdot d z ; \\
D_{12}(x, y, z)=\int_{-\delta_{i j}}^{\delta_{s j}} \frac{v_{y}(T, z)}{1-v_{x}(T, z) \cdot v_{y}(T, z)} \cdot E_{x}(T, z) \cdot z^{2} \cdot d z \\
D_{22}(x, y, z)=\int_{-\delta_{i j}}^{\delta_{s, j}} \frac{1}{1-v_{x}(T, z) \cdot v_{y}(T, z)} \cdot E_{y}(T, z) \cdot z^{2} \cdot d z
\end{gathered}
$$

or

$$
D_{22}(x, y, z)=\int_{-\delta_{i j}}^{\delta_{s j}} \frac{v_{y}(T, z)}{v_{x}(T, z) \cdot\left[1-v_{x}(T, z) \cdot v_{y}(T, z)\right]} \cdot E_{x}(T, z) \cdot z^{2} \cdot d z
$$




$$
\begin{aligned}
& D_{33}(x, y, z)=\int_{-\delta_{i j}}^{\delta_{s j}} G_{x y}(T, z) \cdot z^{2} \cdot d z \\
& N_{1 T}(x, y, z)=\int_{-\delta_{i j} \cdot\left[\begin{array}{c}
\alpha_{x T}(T, z)+ \\
+v_{y}(T, z) \cdot \alpha_{y T}(T, z)
\end{array}\right] \cdot T(x, y, z) \cdot d z ;}
\end{aligned}
$$

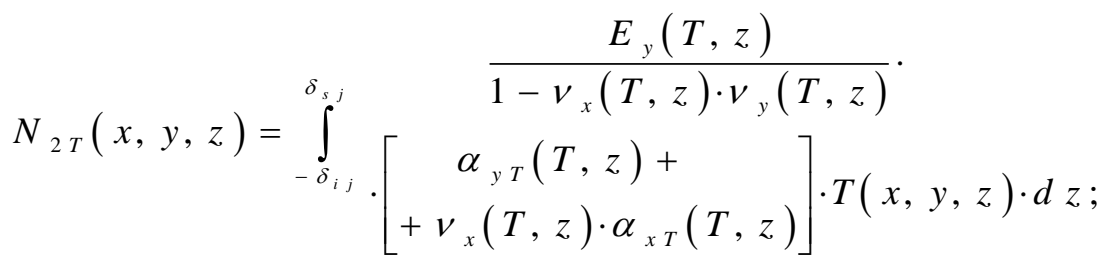

$$
\begin{aligned}
& M_{1 T}(x, y, z)=\int_{-\delta_{i j}}^{\delta_{s j}} \cdot\left[\begin{array}{c}
\alpha_{x T}(T, z)+ \\
+v_{y}(T, z) \cdot \alpha_{y T}(T, z)
\end{array}\right] \cdot z \cdot T(x, y, z) \cdot d z ;
\end{aligned}
$$

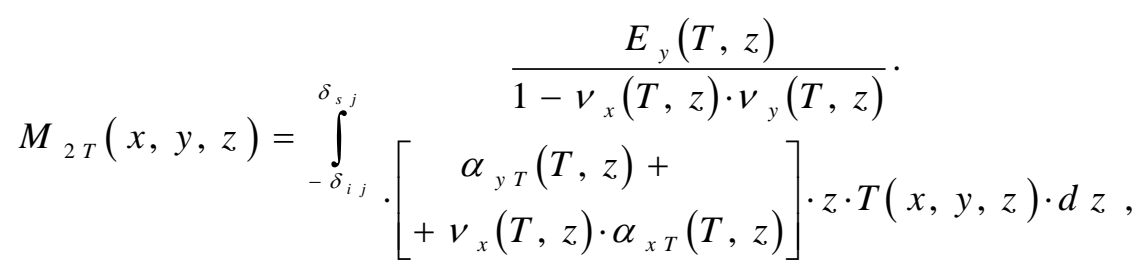

the integration limits are given in Figure 2 (respective dimensions are relative to the neutral surface of the lamina). In the previous relations the following notations are used: $D_{11}(x, y, z), D_{12}(x, y, z)$ - bending stiffness; $D_{22}(x, y, z)$ - torsional rigidity.

Note: In the preceding expression there have been used notations indicated in Figure 2, considering the whole thickness of the lamina represented by the other two dimensions, and measured with respect to mean size of the neutral surface thereof. The indicated sizes for the evaluation of the unit forces and of the bending and twisting moments can be determined if we neglect the effect of temperature and the place of the volume of the composite or not, as appropriate.

\section{ESTABLISHING THE EXPRESSION OF A NEUTRAL SURFACE OF THE LAMINA AND OF A COMPOSITE MULTILAYER}

Note: For small deformations, the following equalities (11) - (13) will be neglected in evaluating the influence of curvature and the normal unit forces $N_{x}, N_{y}$ well as of the longitudinal and shear unit $N_{x y}, N_{y x}$, as a result $A_{11}=A_{12}=A_{22}=A_{33}=0$. Likewise in the Equalities (14) - (16) are kept only the influences offered by the corresponding curves. 


\subsection{The expression of the neutral surface of the lamina/ layer}

As noted in the above, the relations in question shall be taken into discussion the two portions of the overall thickness of the lamina/ layers, from one side and the other of the neutral surface. To determine this position, in the cross - sectional axis Ox, provided $A_{11}=0$ [16]:

$$
\int_{-\delta_{i j}}^{\delta_{s j}}\left[E_{x} /\left(1-v_{x} \cdot v_{y}\right)\right] \cdot z \cdot d z=0
$$

Analysing the structure of expressions $(10-16)$ it is found easily that the equality (11) eliminates curvature influence on normal and shear forces unit.

The following correlation is inserted:

$$
z=z_{0}-\delta_{i j}
$$

so that ( for $z=-\delta_{i j} ; z_{0}=0, z=\delta_{s j} ; z_{0}=\delta_{j}$ );

$$
\int_{0}^{\delta_{j}}\left[E_{x} / 1-v_{x} \cdot v_{y}\right] \cdot\left(z_{0}-\delta_{i j}\right) \cdot d z_{0}=0
$$

respectively:

$$
\int_{0}^{\delta_{j}}\left[E_{x} / 1-v_{x} \cdot v_{y}\right] \cdot z_{0} \cdot d z_{0}-\delta_{i j} \cdot \int_{0}^{\delta_{j}}\left[E_{x} / 1-v_{x} \cdot v_{y}\right] \cdot d z_{0}=0 .
$$

Equality (36) allows determining the share $\delta_{i j}$ under this form:

$$
\delta_{i j}=\left[\int_{0}^{\delta_{j}}\left[E_{x} / 1-v_{x} \cdot v_{y}\right] \cdot z_{0} \cdot d z_{0}\right] /\left[\int_{0}^{\delta_{j}}\left[E_{x} / 1-v_{x} \cdot v_{y}\right] \cdot d z_{0}\right] .
$$

Note: If the elastic modulus is independent of the temperature and the film thickness, the Equality (36) is presented in the form:

$$
E_{x} \cdot \delta_{j} \cdot\left(0,5 \cdot \delta_{j}-\delta_{i j}\right)=0,
$$

from which we deduce:

$$
\delta_{i j}=\delta_{s j}=0,5 \cdot \delta_{j} .
$$

For the case of a laminated metal board with a symmetrical structure in terms of mechanical characteristics, it can be accepted a function of the following type for the module of longitudinal elasticity:

$$
E_{x}(T, z)=a_{E}(T) \cdot z^{2}+b_{E}(T),
$$

in which the parameters indicated in the equality 2 , may have these forms:

$$
a_{E}(T)=4 \cdot\left(E_{M}-E_{m}\right) / \delta_{j}^{2} ; \quad b_{E}(T)=E_{m},
$$


in which $E_{M}, E_{m}$ the modules of longitudinal elasticity is present on the outer surfaces of the board and at its center $\left(E_{M}>E_{m}\right)$, in view of the developed positive influence the lamination process. The modules of longitudinal elasticity may be dependent on temperature.

The phrases above adapt correspondingly to the geometrical elements located in the cross section along the axis $O y$, in which case it shall be considered the longitudinal elastic modulus $E_{y}$.

\subsection{The term of the neutral surface of a laminated composite}

Note: In the following expressions one shall not take into account the presence of adhesive layers. These may be placed in the appropriate adjustment study.

\section{A three-laver composite}

Based on the same logic analysis, by cancelling the expression of the size $A_{11}$, you can reach to:

$$
\left[\delta_{i c}\right]_{3}=\left(I_{11}+I_{12}+I_{13}\right) / I_{21}+I_{22}+I_{23},
$$

in which:

$$
\begin{gathered}
I_{11}=\int_{0}^{z_{01}}\left[E_{x 1} /\left(1-v_{x 1} \cdot v_{y 1}\right)\right] \cdot z_{0} \cdot d z_{0} ; \quad I_{12}=\int_{z_{01}}^{z_{02}}\left[E_{x 2} /\left(1-v_{x 2} \cdot v_{y 2}\right)\right] \cdot z_{0} \cdot d z_{0} ; \\
I_{21}=\int_{0}^{z_{01}}\left[E_{x 1} /\left(1-v_{x 1} \cdot v_{y 1}\right)\right] \cdot d z_{0} ; \quad I_{22}=\int_{z_{01}}^{z_{01} 2}\left[E_{x 2} /\left(1-v_{x 2} \cdot v_{y 2}\right)\right] \cdot d z_{0}, \\
I_{13}=\int_{z_{02}}^{z_{03}}\left[E_{x 3} /\left(1-v_{x 3} \cdot v_{y 3}\right)\right] \cdot z_{0} \cdot d z_{0} ; I_{23}=\int_{z_{02}}^{z_{03}}\left[E_{x 3} /\left(1-v_{x 3} \cdot v_{y 3}\right)\right] \cdot d z_{0},
\end{gathered}
$$

in which:

$$
z_{03}=\delta_{l 1}+\delta_{l 2}+\delta_{l 3} .
$$

Transforming the integral into a sum you can reach at:

$$
\begin{aligned}
\left(\delta_{i c}\right)_{3}= & \frac{\sum_{j=1}^{3}\left\{\left[E_{x j} /\left(1-v_{x j} \cdot v_{y j}\right)\right] \cdot\left[z_{0 j}^{2}-z_{0(j-1)}^{2}\right]\right\}}{2 \cdot \sum_{j=1}^{3}\left\{\left[E_{x j} /\left(1-v_{x j} \cdot v_{y j}\right)\right] \cdot\left[z_{0 j}-z_{0(j-1)}\right]\right\}}= \\
= & \frac{\sum_{j=1}^{3}\left\{\left[E_{x j} /\left(1-v_{x j} \cdot v_{y j}\right)\right] \cdot \delta_{j} \cdot\left(2 \cdot z_{0 j}-\delta_{j}\right)\right\}}{2 \cdot \sum_{j=1}^{3}\left\{\left[E_{x j} /\left(1-v_{x j} \cdot v_{y j}\right)\right] \cdot \delta_{j}\right\}}
\end{aligned}
$$

In the work [15], for a composite sandwich (three layers) type, it is exposed the expression: 


$$
\left(\delta_{i c}\right)_{3}=\frac{E_{1} \cdot \delta_{1}^{2}+E_{2} \cdot \delta_{2} \cdot\left(2 \cdot \delta_{1}+\delta_{2}\right)+E_{3} \cdot \delta_{3} \cdot\left(2 \cdot \delta_{1}+2 \cdot \delta_{2}+\delta_{3}\right)}{2 \cdot\left(E_{1} \cdot \delta_{1}+E_{2} \cdot \delta_{2}+E_{3} \cdot \delta_{3}\right)},
$$

expression in which $\delta_{1}, \delta_{2}, \delta_{3}$ represents the thickness of the lower, the middle and the higher layer . In case $E_{2} \cdot \delta_{2}\left\langle\left\langle E_{1} \cdot \delta_{1}\right.\right.$ and $E_{2} \cdot \delta_{2}\left\langle\left\langle E_{3} \cdot \delta_{3}\right.\right.$ the equality (42"') is reduced to:

$$
\left(\delta_{i c}\right)_{3}=\frac{E_{1} \cdot \delta_{1}^{2}+E_{3} \cdot \delta_{3} \cdot\left(2 \cdot \delta_{1}+2 \cdot \delta_{2}+\delta_{3}\right)}{2 \cdot\left(E_{1} \cdot \delta_{1}+E_{3} \cdot \delta_{3}\right)}
$$

\section{N - Layers composite}

By generalization is reached:

$$
\left[\delta_{i c}\right]_{n}=\sum_{j=1}^{n} I_{1 j} / \sum_{j=1}^{n} I_{2 j}
$$

with the general notations:

$$
I_{1 j}=\int_{z_{0(j-1)}}^{z_{0 j}}\left[E_{x j} /\left(1-v_{x j} \cdot v_{y j}\right)\right] \cdot z_{0} \cdot d z_{0} ; \quad I_{2 j}=\int_{z_{0(j-1)}}^{z_{0 j}}\left[E_{x j} /\left(1-v_{x j} \cdot v_{y j}\right)\right] \cdot d z_{0},
$$

where $E_{x j}$ represents the modulus of longitudinal elasticity for the layer $j, j \in[1,2, \cdots, n]$.

This time, the equality (45) can transform into:

$$
\begin{gathered}
{\left[\left(\delta_{i c}\right)_{n}\right]_{11}=\frac{\sum_{j=1}^{n}\left\{\left[E_{x_{j}} /\left(1-v_{x_{j}} \cdot v_{y_{j}}\right)\right] \cdot\left[z_{0 j}^{2}-z_{0(j-1)}^{2}\right]\right\}}{2 \cdot \sum_{j=1}^{n}\left\{\left[E_{x_{j}} /\left(1-v_{x_{j}} \cdot v_{y j}\right)\right] \cdot\left[z_{0 j}-z_{0(j-1)}\right]\right\}}=} \\
=\frac{\sum_{j=1}^{n}\left\{\left[E_{x_{j}} /\left(1-v_{x_{j}} \cdot v_{y j}\right)\right] \cdot \delta_{j} \cdot\left(2 \cdot z_{0 j}-\delta_{j}\right)\right\}}{2 \cdot \sum_{j=1}^{n}\left\{\left[E_{x j} /\left(1-v_{x j} \cdot v_{y j}\right)\right] \cdot \delta_{j}\right\}}
\end{gathered}
$$

The total thickness of the composite is determined by the expression:

$$
\delta_{c}=z_{0 n}=\sum_{j=1}^{n}\left[z_{0 j}-z_{0(j-1)}\right]=\sum_{j=1}^{n} \delta_{j},
$$

while the thickness of each state is determined by the relationship:

$$
\delta_{j}=z_{0 j}-z_{0(j-1)} .
$$

In the previous expressions it was considered a mean longitudinal elasticity modulus, characteristic of the considered layer (Figure 3). 


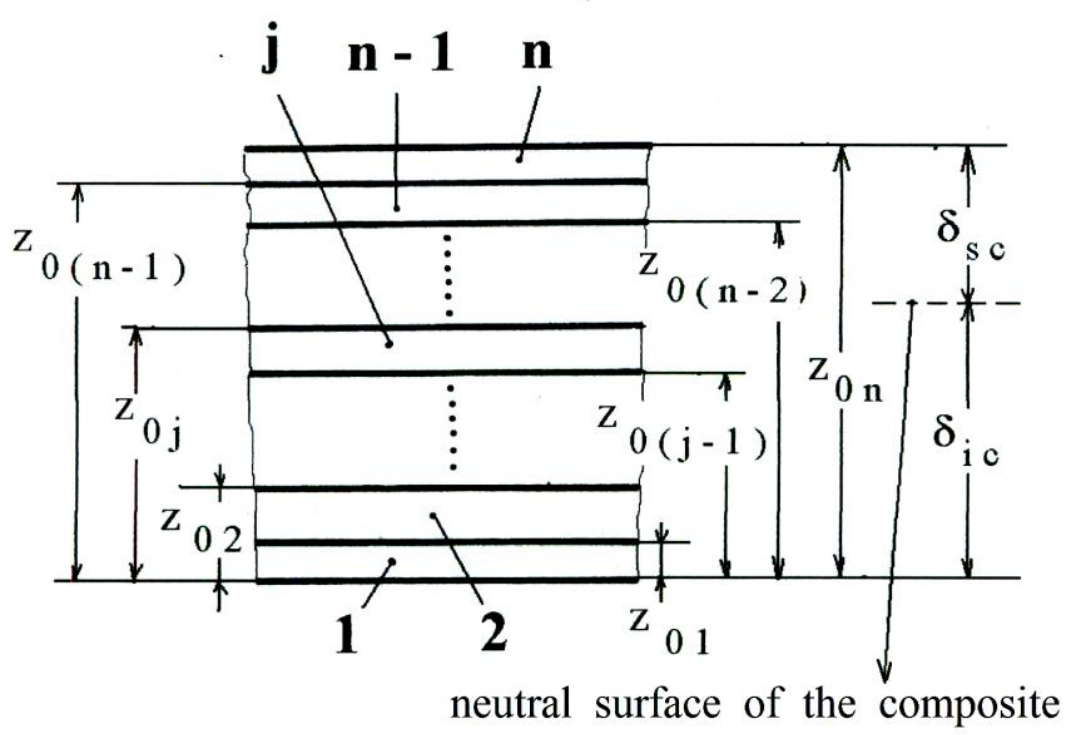

Fig. 3. The position of neutral surface of a layered composite.

Note: For the comparison of the value/ position of the neutral surface indicated above, under the form (45') deducted by cancelling $A_{11}$ size, can be considered the expressions which reflect the cancellation of other sizes as follows:

- Cancellation of expression $A_{12}$ [equality (22)]:

$$
\begin{gathered}
{\left[\left(\delta_{i c}\right)_{n}\right]_{12}=\frac{\sum_{j=1}^{n}\left\{\left[v_{y j} \cdot E_{x j} /\left(1-v_{x j} \cdot v_{y j}\right)\right] \cdot\left[z_{0 j}^{2}-z_{0(j-1)}^{2}\right]\right\}}{2 \cdot \sum_{j=1}^{n}\left\{\left[v_{y j} \cdot E_{x j} /\left(1-v_{x j} \cdot v_{y j}\right)\right] \cdot\left[z_{0 j}-z_{0(j-1)}\right]\right\}}=} \\
=\frac{\sum_{j=1}^{n}\left\{\left[v_{y j} \cdot E_{x j} /\left(1-v_{x j} \cdot v_{y j}\right)\right] \cdot \delta_{j} \cdot\left(2 \cdot z_{0 j}-\delta_{j}\right)\right\}}{2 \cdot \sum_{j=1}^{n}\left\{\left[v_{y j} \cdot E_{x j} /\left(1-v_{x j} \cdot v_{y j}\right)\right] \cdot \delta_{j}\right\}} ;
\end{gathered}
$$

- Cancellation of expression $A_{22}$ [equality (23)]:

$$
\begin{aligned}
{\left[\left(\delta_{i c}\right)_{n}\right]_{22}=} & \frac{\sum_{j=1}^{n}\left\{\left[E_{y j} /\left(1-v_{x j} \cdot v_{y j}\right)\right] \cdot\left[z_{0 j}^{2}-z_{0(j-1)}^{2}\right]\right\}}{2 \cdot \sum_{j=1}^{n}\left\{\left[E_{y j} /\left(1-v_{x j} \cdot v_{y j}\right)\right] \cdot\left[z_{0 j}-z_{0(j-1)}\right]\right\}}= \\
= & \frac{\sum_{j=1}^{n}\left\{\left[E_{y j} /\left(1-v_{x j} \cdot v_{y j}\right)\right] \cdot \delta_{j} \cdot\left(2 \cdot z_{0 j}-\delta_{j}\right)\right\}}{2 \cdot \sum_{j=1}^{n}\left\{\left[E_{y j} /\left(1-v_{x j} \cdot v_{y j}\right)\right] \cdot \delta_{j}\right\}}
\end{aligned}
$$


with consideration of correspondence: $E_{x j} \cdot v_{y j}=E_{y j} \cdot v_{x j}$;

- Cancellation of expression $A_{33}$ [equality (24)]:

$$
\left[\left(\delta_{i c}\right)_{n}\right]_{33}=\frac{\sum_{j=1}^{n}\left\{G_{x y j} \cdot\left[z_{0 j}^{2}-z_{0(j-1)}^{2}\right]\right\}}{2 \cdot \sum_{j=1}^{n}\left\{G_{x y j} \cdot\left[z_{0 j}-z_{0(j-1)}\right]\right\}}=\frac{\sum_{j=1}^{n}\left\{G_{x y j} \cdot \delta_{j} \cdot\left(2 \cdot z_{0 j}-\delta_{j}\right)\right\}}{2 \cdot \sum_{j=1}^{n}\left\{G_{x y j} \cdot \delta_{j}\right\}} .
$$

Note: The check previously suggested takes into account the real fact that the assessment of the physical realelastic is extremely difficult.

\section{CONCLUSIONS}

Based on the assumption of neglecting the effect of spin the cross-section of a composite laminated board in the formulation of the mathematical unit normal and shear forces, on the one hand, and the failure influence of specific linear strains in the expressions of uniform moments of bending and torsion, on the other hand, there are established appropriate expressions to determine the position of the neutral surface. It is justified the analysis for composites whose cross sections have layers with different mechanical and elastic properties uncharacterized by a "mirror" behaviour (state in which the symmetrical positioning of layers determines the cross-sectional area in the mid transversal section).

It is created the conditions of sharing correspondingly the referred burden at the level of the component layers and the possibility of assessing the actual maximum tensions that can be compared to the permissible characteristic construction materials. In this way it offers the possibility of organization the layers correspondingly, so as to ensure safe operation technique, even with the change of the existing materials in the analysis. In a following paper there will be specified the expressions of the distributed tasks in various practical situations, in which case it is possible to analyse delamination layers [26], and respectively the evaluation of the bearing capacity of the adhesives used, effectively neglected in the study, but whose existence allow consideration of the board as a monolithic structure.

\section{REFERENCES}

[1] Zhu, Y., Kedward, K., Methods of analysis and failure prediction for adhesively bonded joints of uniform and variable bondline thickness, Report DOT/FAA/AR - 05/12, U.S. Department of Transportation Federal Aviation Administration, May 2005.

[2] Broughton, R. W., Crocker, E. L., Urquhart, M. J., Strength of adhesive joints: A parametric study, NPC Report MATC (A), July 2001 (http://www.adhesivetoolkit.com/Docu-Data/NPLDocuments/P A J/PAJex/Reports/PAJex1/PAJex1/Report 4 MATC(A)27.pdf- accesat la 23.09.15).

[3] Pugno, N., Carpinteri, A., Tubular adhesive joints under axial load, Journal of Applied Mechanics, Transactions of the ASME, November 2003, 70. p. $832-839$.

[4] De Lorenzis, L., Zavarise G., Cohesive zone modeling of interfacial stresses in plated beams, International Journal of Solids and Structures, 46, 2009, p. $4181-4191$.

[5] Majahar, M. S., Hanumant, P. B., Kolekar, A., Strength evaluation of scare adhesive joints, International Journal in IT and Engineering, vol. 6, no. 6, 2015, p. $1-22$.

[6] Mendeles A. D., Page A. S., Manson E. A. J., A compression - loaded double lap shear test: Part 1, Theory, International Journal of Adhesion and Adhesives, 2002, p. 1 - 26.

[7] Montagnin, M., Modelli previsionali per la resistenza statica di giunzioni incollate in materiale composito, Tesi di Laurea, Università degli studi di Padova, Italy, 2014.

[8] Ritchey, N. T., Development of failure criteria and experimental teseting for composite adhesively bonded scarf repairs utilizing structural paste adhesives, Thesis, Montana State University, USA, 2014. 
[9] Lambert, D. M., Investigation of the design und static behavior of cylindrical tubular composite adhesive joints utilizing the finite element method and stress - based failure theories, Thesis, Utah State university, UZA, 2011.

[10] Baldan, A., Adhesion phenomena in bonded joints, International Journal of Adhesion and Adhesives, vol. 38,2012 , p. $95-116$.

[11] Gustafson, A. P., Waas, M. A., The influence of adhesive constitutive parameters in cohesive zone finite element models of adhesively bonded joints, International Journal of Solids and Structures, vol. 46, 2009, p. $2201-2215$.

[12] Tsai, Y. M., Morton, J., An investigation into the stresses in double - lap adhesive joints with laminated composite adherends, International Journal of Solids and Structures, vol. 47, 2010, p. 3317 - 3325.

[13] Enachescu, G. L., Cercetari teoretice si experimentale privind solicitari termice în placi plane din composite stratificate, aflate în structura echipamentelor pentru procese industriale, Teza de doctorat, Universitatea Politehnica din Bucuresti, 2013.

[14] Iasnicu (Stamate), I., Cercetari privind capacitatea de izolare fonica si rezistenţa mecanica a placilor composite stratificate conţinând deseuri textile recuperate, Teza de doctorat, Universitatea Politehnica din Bucuresti, 2015.

[15]***, Aerospatiale - Composite stress manual, MTS 006 Iss.B, 1999.

[16] Ogibalov, M. P., Gribanov, F. V., Termoustoicivostiplastin i obolociek, Izd. Moskovskogo Universiteta, Moskva, 1968.

[17] Eltaher, A. M., Alshorbagy, E. A., Mahmoud, F. F., Determination of neutral axis position and its effect on natural frequencies of functionally graded macro/nanobeams, Composite Structures, 99, 2013, p. 193 - 201.

[18] Alamoreanu, E., Constantinescu, D. M., Proiectarea placilor compozite laminate, Editura Academiei Române, Bucuresti, 2005.

[19] Iatan, I. R., Popa, T. C., Solicitari termo - mecanice în placi circulare netede, Editura MatrixRom, Bucuresti, 2010.

[20] Iatan, I. R., Placi circulare si inelare, gofrate si perforate, Editura Matrix Rom, Bucuresti, 2012.

[21] Teodorescu, P. P., Probleme spaţiale în teoria elasticitaţii, Editura Academiei Române, Bucuresti, 1970.

[22] Bajanov, L. V., Goldenblat, I. I., Kopnov, A. V., Pospelov, D. A., Siuiukov, M. A., Plastinki i obolociki iz stekloplastikov, Izd. Vâssaia Skola, Moskva, 1970.

[23] Bors, C. I., Teoria elasticitaţii corpurilor anizotrope, Editura Academiei Române, Bucuresti, 1970.

[24] Nettles, T. A., Basic mechanics of laminated composite plates, National Aeronautics and Space Administration (NASA), Reference Publication 1351, Oct. 1994

(http://www.diim.unict.it/users/gmirone/cou/NASA Basic Mechanics of Laminated Plates rp1351.pdf - accesat la 03.08.15).

[25] Sadd, H. M., Elasticity (Theory, Applications, and Numerics), Elsevier Inc. Amsterdam, 2014.

[26] Szekrényes, A., Interlaminar orthotropic composite plates, International Journal of Solids and Structures, 49,2012 , p. $2460-2470$. 